\title{
Safe Childbirth Workshop: Santiago, Chile, October 2008
}

\author{
Patricia Lynch ${ }^{1}$, Akeau Unahalekhaka ${ }^{2}$, Ossama SE Rasslan ${ }^{3}$ \\ ${ }^{1}$ Principal, Epidemiology Associates, Redmond, WA, USA \\ ${ }^{2}$ Faculty of Nursing, Chiang Mai University, Thailand \\ ${ }^{3}$ Medical Microbiology \& Immunology Dept., Ain Shams Faculty of Medicine, Cairo, Egypt
}

doi: 10.3396/ijic.V5i2.022.09

\section{Scope of the problem}

In many parts of the world, very high rates of complications and infections are part of the birth process. Infection prevention is integral to the problem and must be part of the solution. Low cost, effective infection prevention interventions are necessary immediately. ${ }^{1}$

\section{Maternal complications of childbirth}

Each year, more than 529,000 women die from complications during pregnancy, childbirth, or postpartum period. ${ }^{2}$ Maternal mortality is inequitably spread throughout the world: nearly all of maternal deaths occur in developing countries. ${ }^{3}$ The risk of maternal death is 1 in 75 in developing regions compared to 1 in 7,300 in developed regions, but a woman in sub-Saharan Africa has a 1 in 16 chance of dying in pregnancy or childbirth. ${ }^{3}$ The greatest public health indicator that measures differences between poor and rich countries is the maternal mortality ratio (maternal deaths per 100,000 live births). ${ }^{3}$

The high maternal mortality ratio in many countries results from poor health care during pregnancy and childbirth but risks of poor outcomes are exacerbated by poverty, low status of women, lack of education, poor nutrition, heavy workloads and violence. Pregnancy complications are the main cause of death for women aged $15-19 .{ }^{4}$ Women die of a wide range of direct or indirect causes in pregnancy, childbirth or the postpartum period. The four major causes of death are: severe bleeding (mostly postpartum haemorrhage), infections (mostly sepsis), hypertensive disorders in pregnancy (usually eclampsia), and obstructed labour. Complications after unsafe abortion cause $13 \%$ of maternal deaths. Among the indirect causes $(20 \%)$ of maternal death are diseases that complicate pregnancy or are aggravated by pregnancy, such as malaria, anaemia, HIV/AIDS, and cardiovascular diseases. ${ }^{5}$

Besides mortality, an estimated 20 million women endure life long disabilities such as pelvic pain, incontinence, obstetric fistula, anaemia and infertility. ${ }^{2}$ Most maternal deaths are avoidable. ${ }^{5}$ In 2006, only about $60 \%$ of deliveries in developing countries were assisted by a skilled birth attendant. This meant that there were approximately 50 million home deliveries that were not assisted by skilled health personnel. ${ }^{6}$

\section{Neonatal complications of childbirth}

Approximately 4 million neonates die every year in their first 28 days of life, $99 \%$ in low-resource settings; these mostly preventable deaths constitute $38 \%$ of all deaths in children under the age of five years. ${ }^{7}$ Neonatal deaths account for over one-third of the global burden of child mortality. In a major review, reported rates 
of neonatal infections in low-resource settings were 3-20 times higher than those reported for hospital-born babies in industrialised countries. ${ }^{8}$ Neonatal infections alone are estimated to cause 1.6 million annual deaths or $40 \%$ of all neonatal deaths in developing countries.

Direct causes of death in high neonatal mortality (NMR) regions ( $>45 / 1000$ live births) are infection, tetanus and diarrhoea; when NMR is $<15 / 1000$ live births (LB), sepsis and pneumonia are more common, diarrhoea and tetanus non-existent.

Childbirth complications including infections are primarily associated with poverty. They affect women and babies in all countries and are most frequent among those who lack access to adequate care. Researchers who examined the effect of neighbourhood income and maternal education on birth outcomes found a correlation between relative poverty and higher fatalities for babies. There was a significant disparity between death rates in the highest income $20 \%$ (quintile) of the population compared to those in the lowest $20 \% .{ }^{9}$ This relative disparity probably exists in all countries.

Healthcare-associated infections play a significant role in neonatal mortality among hospital-born babies in low-resource settings; in a sample of 12 NICUs in mostly university-affiliated hospitals in developing countries, the International Nosocomial Infections Consortium reports rates 3-5 times greater than those reported by the NHSN in the US. ${ }^{10,11}$ Very few hospitals in developing or extremely low-resource regions conduct surveillance for hospital infections and the true rates should be assumed to be much higher. The importance of hospital infections as a cause of neonatal mortality is corroborated in the experience in Egypt, described below.

\section{Experience in Egypt}

Egypt's maternal mortality ratio fell dramatically from $174 / 100,000$ live births (LB) in 1992 to $84 / 100,000$ LB in 2000. This stunning success was due to application of most or all of the authoritative recommendations in a very short time: improved use of contraceptives and family planning; increased access to hospital delivery; better management of obstetrical emergencies; training for traditional birth attendants that includes new curriculum and educational materials; upgrading rural facilities and personnel. Finally, recognising that improvements in women's education and general health are likely to affect maternal and neonatal mortality, an integrated health and literacy activity incorporating maternal and child health messages into education curricula was developed.

Healthcare-associated neonatal sepsis, mostly from device-related infections and transmission of infectious agents via hands of personnel continues to be a major cause of mortality. This is typical of hospitals without effective infection prevention programs and remains one of the situations in which infection control intervention is essential.

\section{Workshop activity}

Workshop participants (approximately collaborated in three groups.

The first group addressed the question: "What do we need in order to improve safe childbirth for mothers and babies in our immediate region?"

The answer: "Better programs to reach disadvantaged populations including recent immigrants, poor people, substance abusers, isolated populations such as Native Americans in remote areas and very young mothers".

We need programs that specifically provide:

1. Better public health coverage of these populations

2. More nurse practitioners and/or midwives to help manage pregnancies

3. Closer neonatal follow-up

4. Better infection prevention in new-born nurseries and neonatal ICUs

5. Housing for women with high risk pregnancies so they are closer to medical care

6. Improved care for low birth weight babies

7. More local birth attendants who have better training to identify potential complications of pregnancy

8. Improved referral pathway when advanced care is needed

9. Screening for GBS, sexually transmitted diseases, HIV and hepatitis

10. Family planning services

11. Nutritional consultation, weight and blood pressure check

12. Access to clean water 
The second group answered the question, "What can we in this room initiate in service of safer childbirth? What can we contribute?"

1. Schedule discussion of safe childbirth issues at our local, national and regional infection control organisations

2. In partnership with colleagues in maternal-child services, develop education material about pregnancy and childbirth for middle and highschool age children.

3. Contact local and national public health organisations to learn about childbirth issues and encourage making solutions a high priority

4. In our own hospitals:

- Create and sustain improvements in neonatal infection prevention, pregnancy counselling including neonatal care and breastfeeding, and family planning.

- Identify emergency childbirth issues

- Improve infection prevention for neonates, particularly prevention of injection and infusion related infections.

5. Encouragecommunityprogramsforimmunisations, STD testing and appropriate counselling before and during pregnancy

The third group answered the question, "What are specific elements to be included?"

1. Education of young girls and boys, starting from early teenage, in:

- family planning

- prevention of sexually transmitted diseases

- the use of condoms

- baby care

2. Pre-natal care with emphasis on free service with easy access in low-income areas, including

- nutrition,

- immunisation against HBV and tetanus,

- check for HIV, hepatitis B, syphilis, gonorrhoea and group B streptococci.

- education of fathers as well as mothers about hygiene and baby care.
3. In the delivery room:

- Training of midwives and auxiliaries in basic precautions: use of hand disinfectant and gloves, use of plastic aprons.

- Provision of separate delivery rooms where the father or another adult family member can be present, and be taught basic precautions

- Mother and child to be nursed together as a unit

4. Baby post partum:

- Sound routines for umbilical care

- Encourage oral feeding with breast milk from mother or donor

\section{References}

1. Zaidi AK, Huskins WC, Thayer D, et al. Hospital-acquired neonatal infections in developing countries. Lancet 2005; 365: $1175-1188$.

2. Ronsmans C, Graham WJ. Maternal mortality: who, when, where, and why. Lancet 2006; 368: 1189-1200.

3. WHO. Maternal mortality in 2005. Estimates developed by WHO, UNICEF, UNFPA and The World Bank. Geneva, World Health Organization, 2007.

4. UNICEF. Improve Maternal Health. http://www.unicef.org/ mdg/maternal.html [Accessed June 17, 2009]

5. WHO. Make every mother and every child count. Geneva, World Health Organization, The World Health Report. 2005 p. 62.

6. WHO. Proportion of births attended by a skilled health worker - 2008 updates. Geneva, World Health Organization, Department of Reproductive Health and Research, 2008.

7. Zupan J, Aahman E. Perinatal mortality for the year 2000: estimates developed by WHO. Geneva: World Health Organization, 2005.

8. Lawn J, Cousens S, Zupan J. 4 million neonatal deaths: When? Where? Why? Lancet 2005; 365: 891-900.

9. Luo ZC, Kierans WJ, Wilkins R, Liston RM, Mohamed J, Kramer MS. Disparities in birth outcomes by neighborhood income: temporal trends in rural and urban areas, British Columbia. Epidemiology 2004; 15: 679-686.

10. Rosenthal VD, Maki DG, Mehta A, et al. International Nosocomial Infection Control Consortium report, data summary for 2002-2007. Am J Infect Control 2008; 36: 627-637.

11. Edwards JR, Peterson KD, Andrus ML, et al. National Healthcare Safety Network (NHSN) Report, data summary for 2006 through 2007, issued November 2008. Am / Infect Control 2008; 36: 609-626. 